\title{
Cause Traced to Intentional Off-Label, Unapproved, or Contraindicated Use
}

National Cancer Institute

\section{Source}

National Cancer Institute. Cause Traced to Intentional Off-Label, Unapproved, or

Contraindicated Use. NCI Thesaurus. Code C91892.

Problems traced to the intentional use of the device in an unapproved procedure, for an unapproved patient, or for which it is contraindicated, or not listed on the label. 